\title{
Judo's Mental Imagery Training and Technical Acquisitions among High Institute Students
}

\author{
Nasr Chalghaf ${ }^{2}$, Souhir Sbaa ${ }^{1}$, Marc Levêque, Fairouz Azaiez ${ }^{1,2}$ \\ 1- Higher institute of Sport and the Physical Education of Sfax (Tunisia) \\ 2- Studies Group of Development and Social Environment (Faculty of Social Sciences and letters of Sfax)
}

\begin{abstract}
Mental imagery as a cognitive technique is one of the suitable treatment methods to improve athletic performance (Cumming \& al., 2006; Eddy \& al., 2003). It can be defined as using all sense to re-create or create a sport experience in the mind with the goal of enhancing sport performance during training and competition (Morris, Spittle \& Watt., 2005; Taylor \& Wilson., 2005; Weinberg \& Gould., 2007). Our study aims to identify the effect of a learning program of mental imagery method in judo standing on the technical acquisitions. 48 students male divided into three groups of 16 , (mean age $21.0 \pm 1.85$ ) voluntarily participated in this study. Group 1, has a judo mental imagery learning; group 2 has an observational judo learning and group 3 has an analytical judo learning. The revised movement imagery questionnaire (MIQ-R) developed by Hall \& Martin (1997) was used in our study before and after the training programs in order to evaluate the ability of imagery overall the subjects. Also a technical test overall judo tested actions with a three levels scale from $(0=$ without acquisition $),(0.5=$ minimal acquisition $)$ to $(1=$ maximal acquisition $)$. The results of the analytical chi-square calculated in different learning methods are not significant which show us that the three groups presented a similar acquisitions in declarative knowledge justified by the global chi-square, which is significant at $P<.01$.
\end{abstract}

Keywords: mental imagery; judo training; technical acquisition

Submitted Date 14 June 2013

Accepted Date: 19 June 2013

\section{Introduction}

Applied sport psychology has grown and will continue to grow in the coming years. Much research has been done in order to help athletes and coaches to achieve their goals and the importance of mental skills for success in sport is generally accepted. When an athlete is skilful both physically and mentally, the result will be an exceptional performance (Weinberg \& Gould, 2007). Perhaps one of the most widely researched and popular intervention strategies to date has been the use of mental imagery (Cumming, Hall \& Shambrook, 2004). Through imagery, you can re-create previous positive experiences or picture new events to prepare yourself mentally for performance (Weinberg \& Gould, 2007). Research has shown that in comparison to no practice at all, imagery usually benefits performance (Durand, Hall, \& Haslam, 1997). As a result, Hall (2001) has suggested that imagery can serve as an effective supplement to regular physical practice and as a substitute for some amounts of physical practice when athletes are unable to train (Cumming \& al., 2004). Even though research has been intensive in this field, limited research attention has been placed in exact imagery training programs specific for each sport. This study focuses on the use of imagery in judo athletes. Judo is a very demanding sport, both physically and mentally. Mental toughness is a very important determinant of success for the judo athletes. However, there is a lack of literature concerning judo and mental training. Our intention is that this study will manage to provide some useful guidelines to coaches or sport psychology specialists that want to apply imagery training in judo. Because imagery cannot be directly observed, the two skills most regularly examined are "imagery ability" and "imagery use" (Morris, Spittle \& Watt, 2005). In addition, recent studies support the benefit of conducting interventions with youth sport athletes aimed at teaching them the importance and value of using imagery, and how they can effectively incorporate imagery into their regular training (LiWei, Qi-Wei, Orlick, \& Zitzelsberger, 1992; Cumming \& Hall, 2002; Cumming et al., 2004).

\section{Mental Imagery}

Defining mental imagery is a difficult task. Consequently, extensive debate about its characteristics and qualities continues both within and between the various fields of psychology (Morris et al., 2005). There exist various definitions of imagery in the literature. However, in relation to involvement in sport, the most widely used definition is the one provided by Morris et al. (2005) "Imagery, in the context of sport, may be considered as the creation or re-creation of an experience generated from memorial information, involving quasi-sensorial, quasi-perceptual, and quasi-affective characteristics, that is under the volitional control of the 
imager, and which may occur in the absence of the real stimulus antecedents normally associated with the actual experience". Mental imagery involves the athletes' imagery themselves in a specific environment or performing a specific activity. Different uses of imagery in sport include: mental practice of specific performance skills, improving confidence, and positive thinking, problem solving, controlling arousal and anxiety, performance review and analysis, preparation for performance and during imagery, (plessenger., 2009).

Furthermore fisher, (1986) clarifies that imagery is the language of the brain in a real sense, the brain really cannot tell the difference between an actual physical event and the vivid visualization of the same event. For this reason imagery can be used by the brain to provide repetition, elaboration, intensification and preservation of important athletic sequences and skills. Another popular theory is Suinn's visual motor behavior rehearsal (VMBR) model which posits that imagery should be a holistic process that includes a complete reintegration of experience. This includes visual auditory tactile emotional and kinesthetic cues. He has demonstrated that physiological responses can result from athlete's usage of mental imagery. Suinn's method is one of the few which has solid evidence to support its effectiveness, (Suinn 2005).

According to Henschen (2005), often imagery is thought of as synonymous with visualization, but this is inaccurate. Visualization is only one form of imagery. Most athletes are both visual and kinesthetic (feelers) imagers. Strangely enough, the more skilled an athlete becomes normally the more a "feeler" they become. The use of imagery as a mental training technique allows performers to draw on their imagination to prefect their performance.

Anshen, (2004) developed another model known as Anshen's tripe code model of imagery (ISM). According to him, there are three fundamental parts to an image. The first part is that the image itself must be a centrally arousing sensation so it is more like the real world. It has all the attributions of sensation; the only difference is that it is internal. This image provides the imager with so much realism that it can enable him or her to interact with the image as if it were the real world. Secondly there exists a somatic response. Therefore, the very act of imagery results in psycho-physiological changes in the body.

Finally, the third part of the image is the actual meaning of the image; every image has a significant meaning and that specific meaning can imply something different to each individual. Since every person has a unique background and upbringing, the actual internal image can be quite different for each individual, even though the act of imagery instructions is the same, (Murphy, 2005).

\section{Imagery Ability}

Imagery ability refers to the self-reported assessment of the qualities of imagery. All people have the capacity to generate and use images but not in the same degree. Morris (1997) defined imagery ability as "an individual's capability of forming vivid, controllable images and retaining them for sufficient time to effect the desired imagery rehearsal". More recently, Watt, Spittle and Morris (2002) stated that "imagery ability represents the capacity of the individual to create images, and is typically evaluated in terms of generational, sensorial and emotional qualities".

Watt and Morris, based on their research using the Sport Imagery Ability Measure (SIAM), have formulated a model of imagery ability in relation to sport (Watt, Morris, and Andersen, 2004). Imagery literature uses many terms to describe the characteristics that measures of imagery ability assess. The terms "modalities" and "dimensions" are discussed in many studies and reviews. There exist several dimensions in the imagery literature that are relevant to an understanding of the nature of imagery ability in the context of the physical and sport domains. The two dimensions of imagery ability that are most regularly discussed are those of vividness and controllability (Morris et al., 2005). Moran \& al (2011) described vividness of an image, as "its clarity and sharpness or sensory richness". The term "controllability" describes the "ease of accuracy with which an image can be transformed or manipulated in one's mind" (Moran \& al. 2011). Duration is represented by the amount of time an image is clearly maintained in the mind from its initial generation until it disappears (Denis, 1985). The dimension of ease of generation represents the level of ease or difficulty in evoking an image (Morris et al, 2005). The speed of formation of an image is a dimension that warrants investigation in determining the status of imagery skills. Currently, only limited research and analytic discussion of the imagery process proposes the assessment of this attribute (Watt et al, 2004).

\section{Mental Imagery Theories}

There are many theories and body of literature that tried to explain how imagery works but the most popular amongst them are psycho-neuro-muscular, symbolic and informational theories.

\section{Psycho-neuro-muscular Theory}

This theory states that as athletes engage in sport movement, their brains are constantly transmitting impulse to the muscles for execution of the movement. Similar impulses occur in the brain and muscles when athletes imagine the movements without actually performing them. Thus, the psycho-neuro-muscular theory asserts that vivid imagined events produce innervations in our muscles similar to that produced by the actual 
physical execution of the event. Coaches and athletes should know that mental imagery strengthens their muscle memories by having the muscle respond in the correct sequence without actually executing the movement, (Williams \& al., 2010).

\section{Symbolic Learning Theory}

In this theory, imagery may function as a coding system to help athletes acquire or understand movement patterns. All movements that we make must first be encoded in our central narrow system, we must have a blue print or code their movement into symbolic components, thus making the movement more familiar and perhaps more automatic. For example, a gymnast can use imagery to cue himself, on the temporal and spatial elements involved in performing a balance beam routine (Smith \& al. 2007).

\section{Bio-informational theory}

This theory assumes that a mental image is an organized set of propositions or characteristics stored in the brain's long-term memory (Wrisberg 2007). When individuals engage in imagery, they activate stimulus characteristics that describe the content of the image for them and response characteristics that describe what their responses are to the stimuli in that situation. According to bio informational theory, for imagery to facilitate athletic performance, response characteristics must be activated so they can be modified, improved and strengthened. By repeatedly accessing response characteristics for a particular stimulus situation and modifying these responses to represent perfect control and execution of a skill, imagery is predicted to enhance performance, Hecker \& al (1988).

\section{Mental Imagery Training and Technical Acquisitions}

Mental imagery exercises have many important goals which are firstly, to ensure that there is an increase in physical performance, secondly, to remove the negative issues that may occur during competition and finally, to shorten the recovery period in case of any possible injury, (Roberts \& al., 2008). Mental imagery exercises ensure that various psychological states that have negative impacts on athletes are minimized, such as stress, anxiety, concern, motivation disorders, depression, (Bartholomew \& al., 2011). It also ensures that issues that play an important in performance increase improve in positive direction, such as attention, concentration, goal setting, stress management, stimulus control, self-confidence, motivation and communication skills, (Smith $\&$ al., 2011). In case the athlete does envisioning exercises in his/her brain during recovery and return period following injury, it accelerates the healing process in the positive direction as it supports the administered treatment (Gardner \& al., 2006). It is revealed by scientific researches that envisioning exercises make positive contributions to performance increase (Burton \& al., 2008). Envisioning requires experiencing the imagined situation with all of our sense organs. Events that are envisioned clear enough in the mind form stimuli in our brains that are very close to reality (Williams., 2006). Therefore, athletes may benefit from envisioning exercises in order to strengthen, detail, intensify, remember new or former sports skills, and for purposes, such as strategies, sports tactics and techniques, sports rehabilitation, (Mouratidis \& al., 2008).

\section{Methods}

48 male students, who had never done mental imagery exercise previously divided into three groups of 16 , (mean age $21.0 \pm 1.85$ ) voluntarily participated in this study. Group 1 has a learning judo imagery program, group 2 has an observational learning and group 3 has an analytical learning. The experiment lasted 8 weeks with 2 hours of learning per week. The revised movement imagery questionnaire (MIQ-R) developed by Hall \& Martin (1997) was used in our study before and after the training programs in order to evaluate the ability of imagery overall the subjects. Also a technical test overall judo tested actions with a three levels scale from $(0=$ without acquisition $),(0.5=$ minimal acquisition $)$ to $(1=$ maximal acquisition $)$ in order to evaluate the technical acquisition after three training programs among the students who never practiced judo previously. A training program was used in judo branche in order to improve the impact of the judo mental imagery program on the imaging capacity among students who never either practiced this martial art or done mental imagery exercise previously. The students of the Imagery group shall envision for half an hour, 2 days per week the video motor training of judo standing technical actions done by a high level judoka. The observational learning group chowed the same program entire session. The analytical learning group had judo learning by a judo teacher. Before every learning session, in order that the imagery is more effective when participants are in a relaxed state, different relaxation strategies were introduced during the guided imagery sessions. These included progressive relaxations, tense-relax method, breathing relaxation and imagery relaxation and lasted for 5-10 minutes. The three groups followed three different training methods of four judo standing technical actions (Ippon Seoi Nage ; Morote Seoi Nage ; O Uchi Gari ; Ko Uchi Gari ) which will be tested after the training sessions . 


\section{Results}

\section{1-Impact of different learning methods on the technical acquisitions in different skills}

The statistical data showing the effect of the different training methods on the acquisition of different judo's skills overall the experimental groups are presented in table 1:

\begin{tabular}{|c||c||c|c||c||}
\hline \hline & Ippon seoi nage & $\begin{array}{c}\text { Morote seoi } \\
\text { nage }\end{array}$ & O uchi gari & Ko uchi gari \\
\hline \hline Chi Square & 11,6406 & 10,9531 & 8,8906 & 27,6406 \\
\hline \hline DDL & 2 & 2 & 2 & 2 \\
\hline \hline P & 0,0030 & 0,0042 & 0,0117 & 0,0000 \\
\hline \hline Decision & MS at $\mathrm{P}<.01$ & S at $\mathrm{P}<.05$ & S at $\mathrm{P}<.05$ & MS at $\mathrm{P}<.01$ \\
\hline \hline
\end{tabular}

Table 1: statistical values of the effect of different methods on technical acquisition.

The results of the chi square overall the different judo's skills used in our research are very significant at $\mathrm{P}<.01$, significant at $\mathrm{P}<.05$ in the back action (O Uchi Gari), reflecting the acquisition among the tested students depends of the learning methods.

\section{2-Comparative study of the effect of different Training methods on the acquisition of different Skills}

The statistical data showing the effect of the different training methods on the acquisition of different judo's skills overall the experimental groups are presented in table 2:

\begin{tabular}{|c||c||c|c|c||}
\hline & Ippon & Morote & O uchi & Ko uchi \\
\hline \hline Chi Square & 10,4052 & 14,5908 & 14,7716 & 10,7143 \\
\hline \hline DDL & 4 & 4 & 4 & 4 \\
\hline \hline P & 0,0341 & 0,0056 & 0,0052 & 0,0300 \\
\hline \hline Decision & Sat $\mathrm{P}<.05$ & MS at $\mathrm{P}<.01$ & MS at $\mathrm{P}<.01$ & S at $\mathrm{P}<.05$ \\
\hline \hline
\end{tabular}

Table 2 Comparative statistical values of the effect of different methods on technical acquisition among the three experimental groups

The statistical values in Table 2 show, first, that the analytical calculation of the chi- square is very significant at $\mathrm{P}<.01$ among the two judo's skills (morote seoi nage and $\mathrm{O}$ uchi gari), on the other hand it is significant at $\mathrm{P}<.05$ among the other judo's skills ( Ippon seoi nage and Ko uchi gari). These findings explain the technical acquisition among our study population is significantly different. This leads us to identify this difference through the study of percentages overall the four judo's tested skills (FIG 1;2;3;4). 


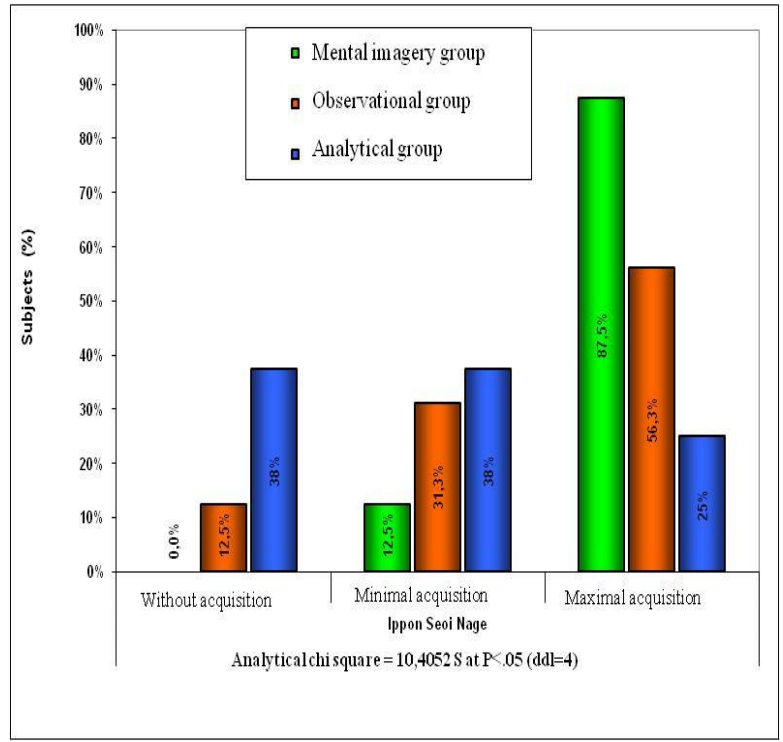

FIG 1: Comparison between the threegroups (ippon seoi nage)

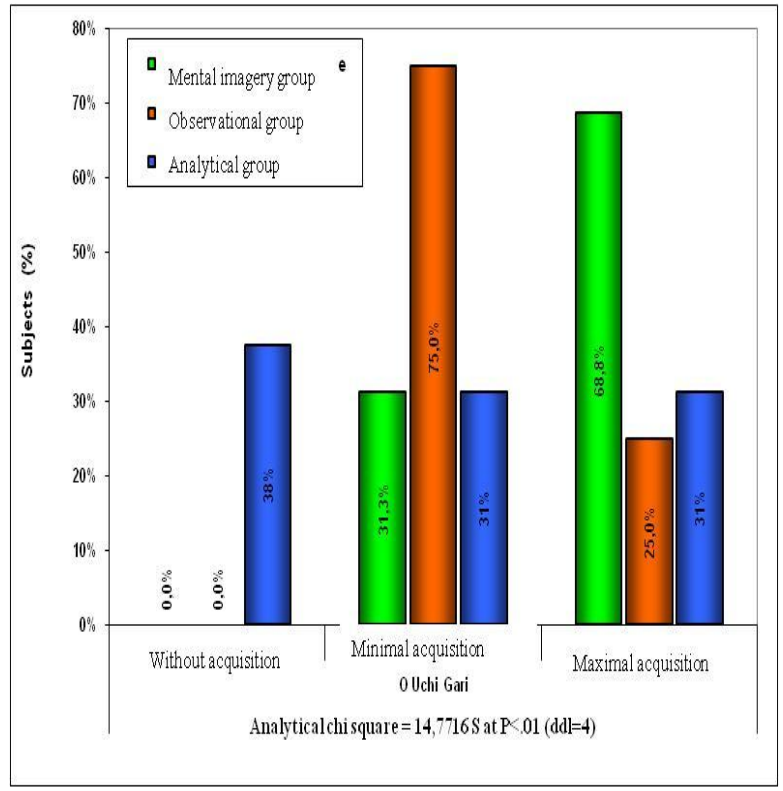

FIG 3: Comparison between the three groups $(O$ Uchi Gari)

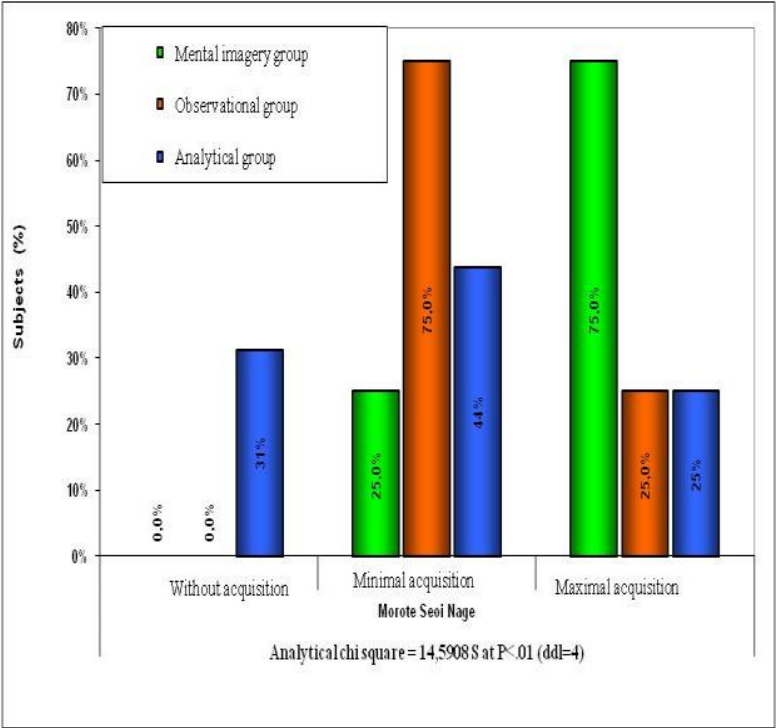

FIG 2: Comparison between the threegroups (Morote Seoi Nage)

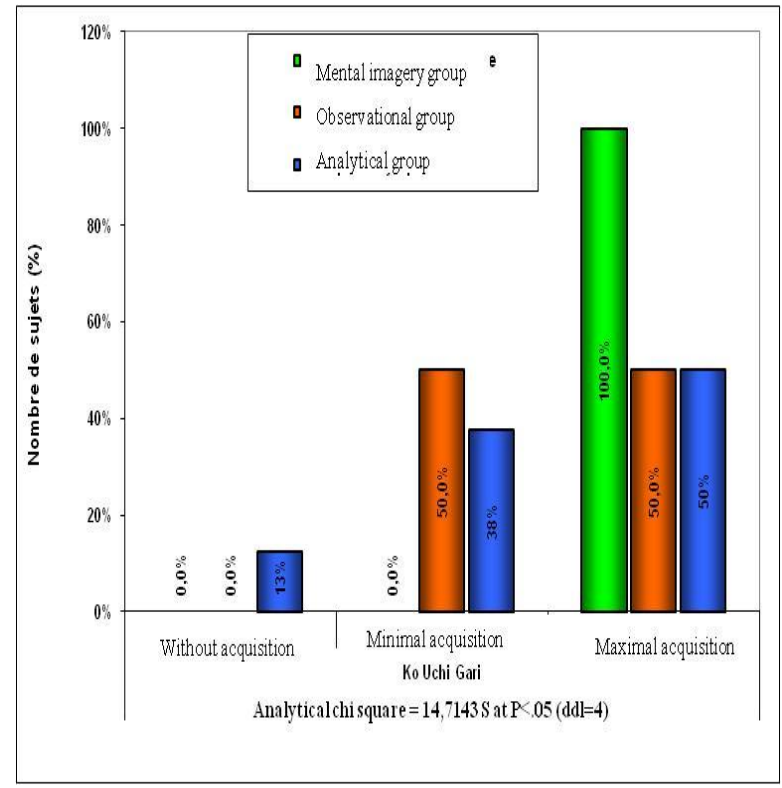

FIG 4: Comparison between the threegroups (KoUchi Gari)

The percentage study of the different judo's skills chows a big difference in favor of the mental imagery group with a maximal acquisitions: (87, $5 \%$ Ippon seoi nage; $75 \%$ morote; $68,8 \%$ o uchi gari et $100 \%$ ko uchi gari). Thus we can note this classification: Mental Imagery Group > Observational Group > Analytical Group.

\section{Discussion}

Our study results show a significant effect of the application of the mental imagery method on the judo's technical acquisitions. The statistical data show a surprising progress of the mental group compared to the two other groups (observational group and the analytical group). These findings go in the same direction as those observed in the work of Crosbie \& al., (2004). Other authors note the importance of imagery in the acquisition of new techniques such as Mulder \& al (2004).

In addition, Fadiga \& Craighero (2004); Jeannrod (2001); Gentili, Papaxanthis \& Pozzo (2006); Mulder \& al (2004); Vieilledent, Kosslyn, Berthoz \& Giraudo (2003) raised the impact of the mental training on the acquisition of "Internal Model" and the individual capacity for abstraction. Beyond that, the acquisition of the internal model is even in the absence of movement (Crosbie \& al, 2004; Dijkerman \& al, 2004). Much more, Voss \& al (2006) found that motor imagery is the equivalent consciousness of the action's prediction. 
These statistical data lead us to affirm our hypothesis because as we said earlier that the mental imagery practice could lead to an acquisition of technical knowledge. The results showing the observable acquisitions are also different comparing the progress of the three experimental groups in favor of the mental group which showed a high assimilation ability due to the method by mental imagery. This confirm with the studies of Sirigu \& Duhamel (2001). As Jeannrod (2001) adds that the virtual action is produced in the brain during motor imagery. This can be explained by the specificity of Judo that requires a great cognitive component, especially in the relationship between Tori and Uke both at the time of randori (flexible fighting) or during the Kata where the opponent is mythically present (Inogai., 1995; Kohey \& al 2006).

\section{Conclusion}

However, we found that the mental imagery practice is an effective tool for technical acquisitions among young Judo practitioners. It remains for us to control, in programmed variables experiments to define the optimal conditions use of mental rehearsal. All this refers to judo's philosophy as Kano (2005) said "Judo teaches us to look for the best possible course of action, whatever the individual circumstances, and help us to understand that worry is a waste of energy. Paradoxically, the man who has failed and one who is at peak of success are in exactly the same position. Each must decide what he will do, next, choose the course that will lead him to the future. The teachings of judo give each the same potential for success, in the former instance guiding a man out of lethargy and disappointment to a state of vigorous activity. If we let ourselves be carried away by success, defeat will inevitably follow victory. One should always be prepared for a contest, even the moment after scoring a victory".

\section{References}

[1]. Cumming, J., Nordin, S.M., Horton, R., Reynolds, S. (2006). Examining the direction of imagery and self-talk on dart-throwing performance and self efficacy. The Sport Psychologist, 20, 257-274.

[2]. Eddy, K., Mellalieu, S.D. (2003). Mental Imagery in Athletes with Visual Impairments. Adapted Physical Activity Quarterly, 20(4): 34768

[3]. Morris, T., Spittle, M., Watt, A.P. (2005). Technical Aids to Imagery. In Imagery in Sport. Champaign, IL: Human Kinetics. pp. 237-266.

[4]. Taylor, J. \& Wilson, G. (2005). Applying Sport Psychology: Four Perspectives. 117-134. Champaign, IL: Human Kinetics.

[5]. Weinberg, R. \& Gould, D. (2007). Foundations of Sport ad Exercise Psychology, (4th ed., 296-317). Champaign, IL: Human Kinetics.

[6]. Hall, C. R., \& Martin, K. A. (1997). Measuring movement imagery abilities: A revision of the Movement Imagery Questionnaire. Journal of Mental Imagery, 21, 143 - 154.

[7]. Cumming, J., Hall, C., \& Shambrook, C. (2004). The influence of an imagery workshop on athletes' use of imagery. Athletic Insight, 6 .

[8]. Durand, M., Hall, C., \& Haslam, I. R. (1997). The effects of combining mental practice and physical practice on motor skills acquisition: A review of the literature and some practical implications. The Hong Kong Journal of Sports Medicine and Sports Science, 4, 36-41.

[9]. Hall, C. (2001). Imagery in sport and exercise. In R. Singer, H. Hausenblas, \& C. Janelle (Eds.),Handbook of Sport Psychology (pp. 529 - 549). New York, NY: John Wiley \& Sons, Inc.

[10]. Li-Wei, A., Qi-Wei, M., Orlick, T., \& Zitzelsberger, L. (1992). The effect of mental-imagery training on performance enhancement with 7 -10-year old children, Sport Psychologist, 6, 230-241.

[11]. Cumming, J., \& Hall, C. (2002). Deliberate imagery practice: Examining the development of imagery skills in competitive athletes. Journal of Sport Sciences, 20, 137-145.

[12]. Plessenger, A. (2009).The effects of Mental Imagery on Athletic performance. Research paper at 2007 Washington D.C. The World Bank.

[13]. Fisher, A.C. (1986). Imagery from a sport psychology perspective. A paper presented at the meeting of the American Alliance for Health, Physical Education, Recreation and Dance, Cincinnati.

[14]. Suinn, R. (2005). Behaviour Rehearsal Training for skill Racers Behaviour Therapy 1. 519 - 520.

[15]. Henschen, K. (2005). Mental Practice: Strategies and Techniques. University of Uttah, Salt Lake City, Utta, U.S.A.

[16]. Anshen, A. (2004). ISM: The triple code model for imagery and psychophysiology, Journal of mental imagery, $8,15-42$

[17]. Murphy, S. (2005). Model of Imagery in Sport Psychology: A Review Journal of Mental Imagery, 14 (3 and 4), 153 - 172.

[18]. Watt, A. P., Morris, T., \& Andersen, M. B. (2004). Issues in the development of a measure of imagery ability in sport. Journal of Mental Imagery, 28, 149-180.

[19]. Morris, T. (1997). Psychological skills training in sport: An overview (2nd ed). Leeds: National Coaching Foundation.

[20]. Moran, A., Guillot, A., MacIntyre, T., \& Collet, C. (2011). Re-imagining motor imagery: Building bridges between cognitive neuroscience and sport psychology. British Journal of Psychology. doi: 10.1111/j.2044-8295.

[21]. Denis, M. (1985). Visual imagery and the use of mental practice in the development of motor skills. Canadian Journal of Applied Sports Science, 10, 4-16.

[22]. Williams, S. E., Cumming, J., \& Balanos, M. G. (2010). The use of imagery to manipulate challenge and threat appraisal states in athletes. JSEP, 32: 339-358.

[23]. Smith, D., Wright, C., Allsopp, A., \& Westhead, H. (2007). It's all in the mind: pettlep-based imagery and sports performance. Journal of Applied Sport Psychology, 19, 80-92.

[24]. Wrisberg, C. A. (2007). Skill instruction for coaches. Champaign, IL: Human Kinetics.

[25]. Hecker, J., \& Kaczor, L. (1988). Application of imagery theory to sport psychology: Some preliminary findings. Journal of Sport and Exercise Psychology, 10, 363-373.

[26]. Roberts, R., Callow, N., Hardy, L., Markland, D., \& Bringer J. (2008). Movement imagery ability: Development and assessment of a revised version of the vividness of movement imagery questionnaire. JSEP, 30:200-221. 
[27]. Bartholomew, K. J., Ntoumanis, N., Ryan, R. M., \& Thogersen-Ntoumani, C. (2011). Psychological need thwarting in the sport context: Assessing the darker side of athletic experience. JSEP, 33:75- 102.

[28]. Smith, A. L., Ntoumanis, N., Duda, J. L., \& Vansteenkiste, M. (2011). Goal striving, coping, and well-being: A prospective investigation of the self-concordance model in sport. JSEP, 33: 124-145.

[29]. Gardner, F., \& Moore, Z. (2006). Clinical Sport Psychology. 2nd. Edition, Human Kinetics, USA.

[30]. Burton, D., \& Raedeke, T. (2008). Sport Psychology for Coaches. 1st. Edition, Human Kinetics, USA

[31]. Williams, J. (Eds). (2006). Applied Sport Psychology Personal Growth to Peak Performance. 5th. Ed, McGraw-Hill, New York.

[32]. Mouratidis, A., Vansteenkiste, M., Lens, W., \& Sideridis, G. (2008). The motivating role of positive feedback in sport and physical education: Evidence for a motivational model. JSEP, 30: 240-268.

[33]. Crosbie, J.H., McDonough, S.M., Gilmore, D.H., Wiggam, M.I. The adjunctive role of mental practice in the rehabilitation of the upper limb after hemiplegic stroke: a pilot study.Clin Rehab 2004;18:60-8.

[34]. Mulder, T., Zijlstra, S., Zijlstra, W., \& Hochstenbach, J. (2004). The role of motor imagery in the learning a totally novel movement. Experimental Brain Research, 154, 211-217.

[35]. Fadiga L., Craighero L. Electrophysiology of action representation. Journal of Clinical Neurophysiology, 2004, 21:157-69.

[36]. Jeannerod, M. (2001) Neural simulation of action : A unifying mechanism for motor cognition. Neuroimage, 14, S103-S109.

[37]. Gentili, R., Papaxanthis, C., Pozzo, T. (2006) Improvement and generalization of arm motor performance through motor imagery practice. Neuroscience 137:761-772.

[38]. Vieilledent, S., Kosslyn, S.M., Berthoz, A. \& Giraudo , MD. (2003): Does mental simulation of following a path improve navigation performance without vision. Cog. Brain Res. 16(2):238-249.

[39]. Dijkerman, H.C, Ietswaart M, Johnston M, MacWalter RS. Does motor imagery training improve hand function in chronic stroke patients? A pilot study. Clin Rehab.2004;18:538-49. [PubMed]

[40]. Voss, M and Ingram, JN and Haggard, P and Wolpert, DM (2006) Sensorimotor attenuation by central motor command signals in the absence of movement. Nature Neuroscience, 9. pp. 26-27.

[41]. Sirigu, A., Duhamel, J.R. (2001). Motor and visual imagery as two complementary but neurally dissociable mental processes. Journal of Cognitive Neuroscience 13, 910-919.

[42]. Inogai,T .(1997). Judo Kata : Les formes classiques du kodokan .Amphora, coll. Encyclopédie des arts martiaux.

[43]. Kohei, M ., Masahiko, Y ., Kouichi, S ., Ayako, F. (2006). Mental training and skills acquisition in judo. Brain research. 16 June.

[44]. Kano, J. (2005). Mind over muscle: Writings from the founder of judo. In Murata,N. (Ed.). Kodansha International. 